\title{
Determinants of maximal oxygen uptake in severe acute hypoxia
}

\author{
J. A. L. CALBET, ${ }^{1,2}$ R. BOUSHEL, ${ }^{2,3}$ G. RÅDEGRAN, ${ }^{2}$ \\ H. SØNDERGAARD ${ }^{2}$ P. D. WAGNER, ${ }^{4}$ AND B. SALTIN ${ }^{2}$ \\ ${ }^{1}$ Department of Physical Education, University of Las Palmas de Gran Canaria, \\ 35017 Las Palmas de Gran Canaria, Spain; ${ }^{2}$ The Copenhagen Muscle Research Centre, \\ Rigshospitalet, 2200 Copenhagen N, Denmark; ${ }^{3}$ Department of Exercise Science, Concordia \\ University, Montreal, Quebec, Canada H4B 1R6; and ${ }^{4}$ Department of Medicine, Section \\ of Physiology, University of California San Diego, La Jolla, California 92093
}

Submitted 11 March 2002; accepted in final form 27 September 2002

\begin{abstract}
Calbet, J. A. L., R. Boushel, G. Rådegran, H. Søndergaard, P. D. Wagner, and B. Saltin. Determinants of maximal oxygen uptake in severe acute hypoxia. Am J Physiol Regul Integr Comp Physiol 284: R291-R303, 2003. First published October 3, 2002; 10.1152/ajpregu.00155.2002.-To unravel the mechanisms by which maximal oxygen uptake $\left(\dot{\mathrm{V}}_{2}\right.$ max $)$ is reduced with severe acute hypoxia in humans, nine Danish lowlanders performed incremental cycle ergometer exercise to exhaustion, while breathing room air (normoxia) or $10.5 \% \mathrm{O}_{2}$ in $\mathrm{N}_{2}$ (hypoxia, $\sim 5,300 \mathrm{~m}$ above sea level). With hypoxia, exercise $\mathrm{Pa}_{2}$ dropped to $31-34 \mathrm{mmHg}$ and arterial $\mathrm{O}_{2}$ content $\left(\mathrm{Ca}_{\mathrm{O}_{2}}\right)$ was reduced by $35 \%(P<$ 0.001). Forty-one percent of the reduction in $\mathrm{Ca}_{\mathrm{O}_{2}}$ was explained by the lower inspired $\mathrm{O}_{2}$ pressure $\left(\mathrm{PI}_{\mathrm{O}_{2}}\right)$ in hypoxia, whereas the rest was due to the impairment of the pulmonary gas exchange, as reflected by the higher alveolar-arterial $\mathrm{O}_{2}$ difference in hypoxia $(P<0.05)$. Hypoxia caused a $47 \%$ decrease in $\dot{\mathrm{V}}_{2}$ max (a greater fall than accountable by reduced $\left.\mathrm{Ca}_{\mathrm{O}_{2}}\right)$. Peak cardiac output decreased by $17 \%(P<$ 0.01 ), due to equal reductions in both peak heart rate and stroke volume $(P<0.05)$. Peak leg blood flow was also lower (by $22 \%, P<0.01$ ). Consequently, systemic and leg $\mathrm{O}_{2}$ delivery were reduced by 43 and $47 \%$, respectively, with hypoxia $(P<0.001)$ correlating closely with $\dot{\mathrm{V}}_{2}$ max $(r=0.98, P<$ 0.001 ). Therefore, three main mechanisms account for the reduction of $\dot{\mathrm{V}}_{2}$ max in severe acute hypoxia: 1) reduction of $\mathrm{PI}_{\mathrm{O}_{2}}$, 2) impairment of pulmonary gas exchange, and 3) reduction of maximal cardiac output and peak leg blood flow, each explaining about one-third of the loss in $\dot{\mathrm{V}}_{2}$ max.
\end{abstract}

cardiac output; fatigue; performance; cardiovascular physiology

IN ACUTE HYPOXIA, maximal exercise capacity is reduced progressively as inspired $\mathrm{O}_{2}$ tension falls $(1,19)$. It is generally accepted that this is due to a reduction in arterial oxygen content $\left(\mathrm{Ca}_{\mathrm{O}_{2}}\right)$, caused by desaturation $(24,29,44)$. At altitudes above $\sim 4,000 \mathrm{~m}$, however, the reduction in the maximal oxygen uptake $\left(\dot{\mathrm{V}}_{2}\right.$ max $)$ and exercise capacity is substantially larger than that expected only from the reduction in $\mathrm{Ca}_{\mathrm{O}_{2}}(1,19)$, which

Address for reprint requests and other correspondence: J. A. L. Calbet, Departamento de Educación Física, Campus Universitario de Tafira, 35017 Las Palmas de Gran Canaria, Canary Islands, Spain (E-mail: lopezcalbet@terra.es). implies that other mechanisms in addition to the lowered $\mathrm{Ca}_{\mathrm{O}_{2}}$ contribute to the reduction in $\mathrm{V}_{2}$ max. For example, alterations in the cardiovascular response to maximal exercise such as a reduced maximal cardiac output (CO) and/or changes in the distribution of blood flow among the organs could also contribute to limit exercise capacity, especially in very severe acute hypoxia.

During submaximal exercise, even a substantial decrease in $\mathrm{Ca}_{2}$ can be compensated for by counterbalancing increases of $\mathrm{CO}$ and skeletal muscle blood flow such that $\mathrm{O}_{2}$ delivery is maintained $(17,30,31,39,49)$. At maximal exercise, however, systemic and muscular blood flow may be reduced depending on the exercise model and the degree of hypoxia (11). During whole body exercise with moderate hypoxia $\left(\mathrm{F}_{\mathrm{I}_{2}} \sim 0.12\right)$, maximal $\mathrm{CO}$ is similar to that attained during normoxic exercise $(21,23,44)$. By comparison, a slightly greater level of hypoxia $\left(\mathrm{F}_{\mathrm{O}_{2}}=0.11\right)$ results in a small decrease in maximal $\mathrm{CO}(30)$, seen with two leg-kneeextension exercise, which recruits only the muscle mass of both quadriceps muscles. In contrast, peak CO is unaffected during normoxic two-legged knee-extension exercise when $\mathrm{Ca}_{\mathrm{O}_{2}}$ is reduced by other means (31) implying that $\mathrm{Pa}_{\mathrm{O}_{2}}$ may influence the maximal pumping capacity of the heart separately from convective $\mathrm{O}_{2}$ availability in severe acute hypoxia.

Similarly, during upright cycle ergometer exercise, maximal leg blood flow (LBF) is reported to be similar during normoxia and moderate acute hypoxia $\left(\mathrm{F}_{\mathrm{O}_{2}}=\right.$ $0.12)(9,29)$. Yet, recent studies showed that a slightly greater level of hypoxia $\left(\mathrm{F}_{\mathrm{IO}_{2}}=0.11\right)$ reduced maximal LBF during exercise with the two leg-knee-extension ergometer (30). Thus, it is unknown whether severe acute hypoxia causes a substantial reduction in maximal CO and LBF during whole body exercise. Also of interest in this regard is whether the partitioning of $\mathrm{CO}$ between locomotor muscles and other body tissues is altered with severe acute hypoxia. One possibility is

The costs of publication of this article were defrayed in part by the payment of page charges. The article must therefore be hereby marked "advertisement" in accordance with 18 U.S.C. Section 1734 solely to indicate this fact. 
that at maximal exercise in severe hypoxia, the fraction of the $\mathrm{CO}$ directed to the exercising muscles is enhanced to preserve $\mathrm{O}_{2}$ delivery to those tissues. In this case, leg vascular conductance and/or perfusion pressure should increase. Alternatively, priority could be given to other tissues, which may require a higher blood flow to maintain normal function when $\mathrm{Ca}_{2}$ is dramatically reduced. If the latter occurs, leg vascular conductance should be decreased. Resolving these issues is critical to unraveling the mechanisms by which $\dot{\mathrm{V}}_{2}$ max is so dramatically affected by severe acute hypoxia.

Therefore, the purpose of this study was to examine oxygen transport and hemodynamic responses in humans during submaximal and maximal exercise under severe acute hypoxia. Special emphasis was focused on the perfusion of locomotor muscles and, hence, muscular $\mathrm{O}_{2}$ delivery at maximal exercise. Upright cycling exercise was used to create a condition in which peripheral $\mathrm{O}_{2}$ demand taxes the maximal pumping capacity of the heart. To challenge $\mathrm{O}_{2}$ delivery to the central nervous system (CNS), we chose an $\mathrm{F}_{\mathrm{I}_{2}}$ low enough to reduce $\mathrm{Pa}_{2}$ to $30-35 \mathrm{mmHg}$. This level of hypoxia is very close to the limit that can be tolerated for a short time by an unacclimatized human and is similar to that reported in resting altitude-acclimatized subjects at the summit of Mt. Everest (37). We hypothesized that during whole body exercise in severe acute hypoxia, maximal oxygen uptake is reduced by more than lowered $\mathrm{Ca}_{\mathrm{O}_{2}}$ (caused by desaturation). It is further impaired by reduced peak $\mathrm{CO}$ and muscle blood flow. A reduction in maximal blood flow might be expected if severe hypoxaemia impairs myocardial contractile function or inhibits the cardiovascular output drive from medullary vasomotor nuclei.

\section{METHODS}

\section{Subjects}

Nine healthy, physically active, Danish lowlanders (5 males and 4 females) volunteered to participate in these studies. Their mean $( \pm \mathrm{SE})$ age, height, and weight were $24.3 \pm 0.5 \mathrm{yr}, 176 \pm 3 \mathrm{~cm}$, and $74 \pm 4 \mathrm{~kg}$, respectively. Each subject's health status was assessed by a complete medical history and physical examination. All were normal in respect to resting ECG, liver, kidney, and thyroid functions, and fasting plasma glucose and electrolyte concentrations. The iron status of both males and females was also normal, as reflected by blood hemoglobin concentrations (145 \pm 4 and $124 \pm 3 \mathrm{~g} / \mathrm{l})$ and plasma concentrations of ferritin $(69 \pm 19$ and $22 \pm 8 \mu \mathrm{g} / \mathrm{l})$ and transferrin $(31.3 \pm 0.6$ and $33.0 \pm 1.4$ $\mu \mathrm{mol} / \mathrm{l}$, respectively). As a part of preliminary examinations, subjects performed a normoxic incremental exercise test to exhaustion on a cycle ergometer (120-W initial work rate increased by $40 \mathrm{~W}$ every $1 \mathrm{~min}$ ) and their $\mathrm{V}_{2}$ max averaged $59 \pm 2 \mathrm{ml} \cdot \mathrm{kg}^{-1} \cdot \mathrm{min}^{-1}$ (range: $49-62 \mathrm{ml} \cdot \mathrm{kg}^{-1} \cdot \mathrm{min}^{-1}$ ) and $53 \pm 4 \mathrm{ml} \cdot \mathrm{kg}^{-1} \cdot \mathrm{min}^{-1}\left(\right.$ range: $\left.47-63 \mathrm{ml} \cdot \mathrm{kg}^{-1} \cdot \mathrm{min}^{-1}\right)$ in the males and females, respectively. These $\dot{\mathrm{V}}_{2}$ max values are $\sim 20 \%$ higher than those reported for the general Danish population of similar age (3) but 20-30\% lower than elite endurance athletes. Experimental interventions were conducted in a hospital under medical supervision. All subjects were informed about the procedures and risks of the study before giving written informed consent to participate as approved by the Copenhagen and Fredriksberg Ethical Committee. The "Guiding Principles For Research Involving Animals and Human Beings" of the American Physiological Society were strictly followed (2).

\section{Experimental Preparation}

Two catheters (femoral artery and femoral vein) and a thermistor (femoral vein) were placed using sterile technique. Briefly, an 18-gauge, 20-cm-long catheter (Hydrocath, Ohmeda, Swindon, UK) was inserted percutaneously under local anesthesia (2\% lidocaine) in the femoral vein of either the right or left leg using the Seldinger technique. This catheter was introduced $2 \mathrm{~cm}$ below the inguinal ligament and advanced $7 \mathrm{~cm}$ distally. The femoral vein catheter was used for venous sampling and downstream cold saline injection. Subsequently, a thin polyethylene-coated thermistor (model 94-030-2.5F T. D. Probe, Edwards Edslab, Baxter, Irvine, CA) was inserted $3 \mathrm{~cm}$ below the inguinal ligament and advanced proximally $10 \mathrm{~cm}$ into the same femoral vein. A second 18-gauge catheter was placed into the femoral artery $2 \mathrm{~cm}$ below the inguinal ligament and advanced $14 \mathrm{~cm}$ proximally. The catheters and thermistor were sutured to the skin to minimize the risk of movement. Both catheters were then connected to a three-way stopcock and fixed to facilitate easy access during the exercise. An additional catheter was placed in a vein in the left upper arm for the injection of the Cardio-green dye for measurement of $\mathrm{CO}$. After the catheters were placed, the subjects rested in the supine position for 30 min.

\section{Experimental Design}

All subjects participated previously in similar experiments during normoxia and hypoxia and were familiar with exercise on the cycle ergometer. Subjects performed upright cycling exercise at sea level (barometric pressure $=750-760$ $\mathrm{mmHg}$ ) breathing either room air (normoxia) or air from a tank consisting of $10.5 \% \mathrm{O}_{2}$ in nitrogen (hypoxia). Two different kinds of exercise were tested: submaximal constant intensity and incremental exercise on the cycle ergometer (Monark 824 E, Vadberg, Sweden) until exhaustion. Thirty minutes after catheterization, subjects sat on the cycle ergometer and breathed through a two-way valve inspiring room air or the hypoxic gas mixture, starting 5 min before resting measurements (Fig. 1). Subjects then performed the submaximal exercise bout, cycling at $102-141 \mathrm{~W}$ (at 80 revolution/min). This intensity corresponded to the highest intensity they could tolerate for $10 \mathrm{~min}$ when exercising in acute hypoxia (10). Measurements were made at 6 and 10 min. Subsequently, after resting for 20-30 min, incremental exercise was started with an initial intensity identical to that used in the submaximal test, which was maintained for 2 $\min$. Then the exercise intensity was increased by $\sim 20-40 \mathrm{~W}$ every min until reaching the maximal workload as determined in the pretest. Load increments were adjusted such that the exercise duration of the incremental exercise tests was $\sim 6-7 \mathrm{~min}$ in all conditions. Normoxic and hypoxic submaximal exercise bouts were administered in random order. When submaximal hypoxic exercise was performed first, the recovery periods were extended when needed, to allow venous blood lactate to reach similar values to those observed at rest. After the submaxial exercise, the normoxic maximal tests were carried out and, then, after at least $1 \mathrm{~h}$ of rest in the semirecumbent position breathing room air, the acute hypoxia tests were performed. Just at the end of the exercise with hypoxia, subjects were vigorously encouraged to keep 


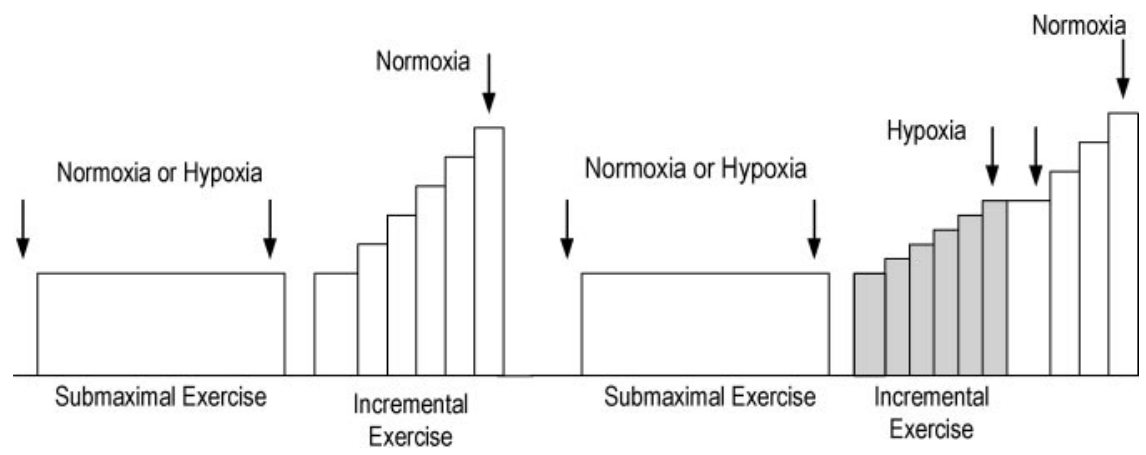

Fig. 1. Experimental protocol. Vertical arrows indicate the time points at which measurements were performed.

pedalling while they were switched to breathing room air. After 2 min at the peak work rate (Wmax) attained in the hypoxic trial, the workload was increased again in steps of 20-40 W until exhaustion.

Although hypoxia was well tolerated by all subjects during exercise, this was not the case at rest. Some subjects experienced exaggerated hyperventilation and paresthesias after 3 min of hypoxic breathing, which were alleviated by the beginning of exercise. To minimize the risk of hypotension and loss of consciousness, ECG and intra-arterial blood pressure were monitored continuously. To avoid any interruption of blood pressure recordings, no blood gas samples were taken at rest during hypoxia. However, in follow-up studies, with more experience it was possible to obtain resting blood gas samples in the same conditions in six subjects of similar age and physical characteristics and results are reported in Table 1. Hypoxia elicited a marked respiratory alkalosis at rest due to exaggerated hyperventilation. Notably, just after 5 min of hypoxic breathing, one subject reached an arterial $\mathrm{pH}$ of 7.65, with a $\mathrm{PaCO}_{2}$ of $18 \mathrm{mmHg}$ and a $\mathrm{PaO}_{2}$ of $64 \mathrm{mmHg}$. As a consequence, he suffered paresthesias, carpal spasms, and dizziness that disappeared completely after interrupting the experiment and allowing him to return to normoxic breath- ing. It should be emphasized then that this level of hypoxia is very close to the limit that a human can tolerate acutely at rest.

\section{Measurements}

Respiratory variables. Pulmonary $\dot{\mathrm{V}}_{2}, \mathrm{CO}_{2}$ production

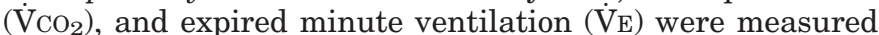
with an on-line system (Medical Graphics CPX, Saint Paul, Minneapolis, MN) while the subjects breathed through a low-resistance breathing valve and averaged every $15 \mathrm{~s}$. Gases with known $\dot{\mathrm{VO}}_{2}$ and $\mathrm{V}_{\mathrm{CO}_{2}}$ concentration (micro-Scholander) were used for gas analyzer calibration.

Blood flow. Femoral venous blood flow (i.e., LBF) was measured in the femoral vein by constant-infusion thermodilution as described in detail elsewhere (4). Briefly, iced saline was infused through the femoral vein catheter at flow rates sufficient to decrease blood temperature at the thermistor by $0.5-1^{\circ} \mathrm{C}$. Infusate and blood temperature were measured continuously during saline infusion (Harvard pump, Harvard Apparatus, Millis, MA) via thermistors connected to the data-acquisition system (MacLab 16/s ADInstruments, Sydney, Australia). Infusate temperature was measured with a

Table 1. Femoral arterial and venous blood gases and acid-base balance at rest and during submaximal and maximal exercise during normoxia and severe acute hypoxia

\begin{tabular}{|c|c|c|c|c|c|c|c|c|}
\hline & \multicolumn{2}{|c|}{$\mathrm{Po}_{2}, \mathrm{mmHg}$} & \multicolumn{2}{|c|}{$\mathrm{PCO}_{2}, \mathrm{mmHg}$} & \multicolumn{2}{|c|}{$\mathrm{pH}$} & \multicolumn{2}{|c|}{$\mathrm{HCO}_{3}^{-}, \mathrm{mmol} / \mathrm{l}$} \\
\hline \multicolumn{9}{|l|}{ Artery } \\
\hline $120 \mathrm{~W}$ & $101 \pm 2$ & $31 \pm 1^{*}$ & $38 \pm 1$ & $27 \pm 1^{*}$ & $7.39 \pm 0.01$ & $7.42 \pm 0.01 *$ & $22 \pm 1$ & $17 \pm 1^{*}$ \\
\hline $\operatorname{Max}$ & $102 \pm 3$ & $34 \pm 1 * \dagger$ & $33 \pm 1 \dagger$ & $25 \pm 1^{*}$ & $7.28 \pm 0.02 \dagger$ & $7.37 \pm 0.02 * \dagger$ & $15 \pm 1 \dagger$ & $15 \pm 1$ \\
\hline \multicolumn{9}{|l|}{ Vein } \\
\hline Rest & $29 \pm 2$ & $24 \pm 2$ & $47 \pm 2$ & $42 \pm 2$ & $7.38 \pm 0.01$ & $7.42 \pm 0.01$ & $27 \pm 1$ & $25 \pm 1$ \\
\hline \multirow{2}{*}{$\operatorname{Max}$} & \multicolumn{2}{|c|}{ Hemoglobin $\mathrm{O}_{2}$ Saturation, $\%$} & \multicolumn{2}{|c|}{$\mathrm{O}_{2}$ Content, $\mathrm{ml} / \mathrm{l}$} & \multicolumn{2}{|c|}{ Base Excess, mmol/l } & \multicolumn{2}{|c|}{ Lactate, $\mathrm{mmol} / \mathrm{l}$} \\
\hline & Normoxia & Hypoxia & Normoxia & Hypoxia & Normoxia & Hypoxia & Normoxia & Hypoxia \\
\hline \multicolumn{9}{|l|}{ Artery } \\
\hline Rest & $97.6 \pm 0.1$ & $82.3 \pm 3.1$ & $180 \pm 7$ & $166 \pm 9$ & $0.1 \pm 0.4$ & $1.5 \pm 0.7$ & $0.8 \pm 0.1$ & $1.3 \pm 0.2$ \\
\hline Max & $13.9 \pm 1.9 \dagger$ & $7.4 \pm 1.6^{*}$ & $28 \pm 5 \dagger$ & $15 \pm 4^{* \dagger}$ & $-11 \pm 1.0 \dagger$ & $-9.7 \pm 1.3^{* \dagger}$ & $9.7 \pm 0.5 \dagger$ & $9.5 \pm 0.9 \dagger$ \\
\hline
\end{tabular}

Values are means \pm SE. Resting values in hypoxia were obtained in 6 subjects of similar characteristics, after $3-5$ min breathing the same hypoxic gas mixture (i.e., $10.5 \% \mathrm{O}_{2}$ in $\mathrm{N}_{2}$ ). ${ }^{*} P<0.05$ compared with the same condition in normoxia; $\dagger P<0.05$ compared with submaximal exercise. 
flow-through housing (model 93-505, Edslab) hooked to the venous catheter luer-lock port. At rest, saline infusions were continued for at least $60 \mathrm{~s}$, while during exercise, 15- to 20-s infusions were used until femoral vein temperature had stabilized at its new lower value. Blood flow was calculated on thermal balance principles, as detailed by Andersen and Saltin (4). Resting blood flow was measured in triplicate and averaged. During submaximal exercise, blood flow measurements were performed in duplicate at 6 and $9 \mathrm{~min}$. The reported values represent the average of the four measurements. At peak effort, the measurements were made within 1 min of exhaustion. When possible, duplicate measurements of $\mathrm{LBF}$ and femoral arteriovenous $\mathrm{O}_{2}$ differences were made during the brief period of peak exercise. Heart rate (HR), arterial blood pressure, pulmonary $\dot{\mathrm{VO}}_{2}, \dot{\mathrm{V}} \mathrm{CO}_{2}$, and $\dot{\mathrm{V}} \mathrm{E}$ were measured at the same time as LBF and CO.

Blood pressure and HR. Arterial blood pressure was monitored continuously by a disposable transducer (T100209A, Baxter, Unterschleissheim, Germany) placed at the level of the inguinal ligament. A three-lead ECG was measured and displayed on a monitor during the experimental and recovery phases. HR was obtained either from the pressure curve or from the continuously recorded ECG. The blood pressure transducer and the ECG electrodes were interfaced with a monitor (Dialogue 2000, Danica, Copenhagen, Denmark), which was, in turn, connected to the data-acquisition system. Systolic and diastolic arterial pressures were computed from the recorded pressure wave, as the maximum and minimum values registered in each cardiac cycle. Mean arterial blood pressure (MAP) was calculated as the integral of the pressure-wave curve over time. Average values corresponding to the blood flow measurement period were recorded for further calculations.

$C O$. CO was measured by indocyanine green (ICG; Akorn, IL) dye-dilution (15). Five to eight milligrams of dye were injected rapidly into the forearm vein followed by a $10-\mathrm{ml}$ flush of isotonic saline. Blood from the femoral artery was withdrawn by a pump (Harvard, 2202A) at $20 \mathrm{ml} / \mathrm{min}$ through a linear photodensitometer (Waters CO-10, Waters Instruments, Rochester, MN) for measurement of the arterial dye concentration. The withdrawn blood $(\sim 20 \mathrm{ml})$ was reinfused after each determination. The dye curves were displayed on a chart recorder (Gould 8000) and extrapolated with a logarithmic scale based on the exponential decay (downslope) observed from 75 to $50 \%$ of the peak dye concentration to correct for recirculation. $\mathrm{CO}$ was then computed as the ratio of dye injected to the average arterial ICG concentration over the time interval of the curve and expressed per minute. After each experiment, an ICG calibration curve was derived from measuring the deflection from three separate 25-ml blood samples with varying concentrations of ICG.

Blood analysis. Blood hemoglobin concentration $([\mathrm{Hb}])$ and $\mathrm{O}_{2}$ saturation $\left(\mathrm{SO}_{2}\right)$ were measured with a cooximeter (OSM 3 Hemoximeter, Radiometer, Copenhagen, Denmark). $\mathrm{PO}_{2}$, $\mathrm{PCO}_{2}$, and $\mathrm{pH}$ were determined with a blood gas analyzer (ABL 5, Radiometer, Copenhagen, Denmark) and corrected for measured femoral vein blood temperature. From these values, plasma $\mathrm{HCO}_{3}^{-}$and actual base excess (BE) were determined as described by Siggaard-Andersen (43). As reduced hemoglobin has a higher buffer capacity than fully oxygenated, BE was adjusted in each blood sample to fully oxygenated $\mathrm{Hb}\left(\mathrm{BE}_{\mathrm{adj}}\right)$ (43). Hematocrit was determined by microcentrifugation on triplicate samples. Arterial and venous $\mathrm{O}_{2}$ content $\left(\mathrm{Ca}_{\mathrm{O}_{2}}\right.$ and $\left.\mathrm{Cv}_{\mathrm{O}_{2}}\right)$ were computed from the saturation and $[\mathrm{Hb}]$ \{i.e., $\left.\left(1.34[\mathrm{Hb}] \times \mathrm{SO}_{2}\right)+\left(0.003 \times \mathrm{PO}_{2}\right)\right\}$. Plasma $\mathrm{K}^{+}$and blood lactate and glucose were measured with an electrolyte metabolite analyzer (EML 105, Radiometer, Copenhagen, Denmark). Plasma norepinephrine and epinephrine concentrations were measured by HPLC with electrochemical detection (20).

\section{Calculations}

Arteriovenous $\left[\mathrm{O}_{2}\right]$ difference (a- $\mathrm{V}_{2}$ diff) was calculated from the difference in femoral arterial and femoral venous $\left[\mathrm{O}_{2}\right]$. This difference was then divided by arterial concentration to give $\mathrm{O}_{2}$ extraction. Oxygen delivery was computed as the product of blood flow and $\mathrm{Ca}_{2}$. $\mathrm{Leg} \dot{\mathrm{VO}}_{2}$ was calculated as the product of $\mathrm{LBF}$, and the a-V $\mathrm{V}_{2}$ diff. Non-leg $\dot{\mathrm{V}}_{2}$ was computed as the difference between pulmonary $\mathrm{VO}_{2}$ and $2 \times$ leg $\mathrm{VO}_{2}$. Leg plasma flow (LPF) was calculated as the product of LBF and (1 - hematocrit). Leg lactate and proton release were calculated as the product of $\mathrm{LBF}$ and the venousarterial difference of lactate and $\mathrm{BE}_{\mathrm{adj}}$, respectively.

\section{Statistical Analysis}

Differences in the measured variables among conditions and exercise levels were analyzed with two-way ANOVA for repeated measures, with condition and exercise intensity as within-subjects factors. When $F$ was significant in the ANOVA, planned pair-wise-specific comparisons were carried out using Student's paired $t$-test adjusted for multiple comparisons with the Bonferroni procedure. Simple linear regression analysis was performed to determine linear relations between variables. Significance was accepted at $P<$ 0.05. Data are reported as means $\pm \mathrm{SE}$.

\section{RESULTS}

\section{Blood Gases and Acid-Base Status}

Severe acute hypoxia markedly reduced femoral arterial and venous $\mathrm{PO}_{2}, \mathrm{O}_{2}$ saturations, and contents at rest and during submaximal and maximal exercise (Table 1). Acid-base balance was also affected by hypoxia. $\mathrm{Pa}_{2}$ and $\mathrm{Pv}_{\mathrm{CO}_{2}}$ were consistently lower during hypoxia than normoxia (Table 1). In contrast, hypoxia attenuated the exercise-induced drop in arterial and venous $\mathrm{pH}$, such that $\mathrm{pH}$ was higher during hypoxia at submaximal and maximal exercise than it was during normoxia. In addition, hypoxia elicited predictable increases in arterial and venous $\mathrm{pH}$ at rest. Hypoxia also lowered plasma $\mathrm{HCO}_{3}{ }^{-}$and base excess in the femoral artery and vein during submaximal exercise. At maximal exercise, however, base excess was less reduced with hypoxia, whereas plasma $\mathrm{HCO}_{3}^{-}$values were equal for two conditions (Table 1).

\section{Hemodynamics and $\dot{V}_{2}$}

Submaximal exercise $(\sim 120 \mathrm{~W})$. Pulmonary ventilation was $72 \%$ higher in hypoxia than in normoxia (Fig. $2 A)$, resulting in higher $\mathrm{V}_{\mathrm{CO}_{2}}(2.2 \pm 0.1$ vs. $1.8 \pm 0.1$ $1 / \mathrm{min}, P<0.001$ ) and arterial $\mathrm{pH}$ (Table 1 ), as well as lower arterial $\mathrm{PCO}_{2}$ in hypoxia than in normoxia (Table 1). The alveolar-arterial $\mathrm{Po}_{2}$ difference $\left(\mathrm{A}-\mathrm{aDO}_{2}\right)$ was also increased from $7.1 \pm 1.6 \mathrm{mmHg}$ in normoxia to $22.2 \pm 1.1 \mathrm{mmHg}$ in hypoxia (Fig. 2C). Despite hyperventilation, $\mathrm{Ca}_{\mathrm{O}}$, was reduced by $35 \%$ during submaximal exercise with acute hypoxia (Table 1). Whole body (pulmonary) $\mathrm{V}_{2}$ during both conditions was similar (Fig. $2 D$ ) owing to the increases in $\mathrm{CO}(21 \%)$ and $\mathrm{LBF}$ $(25 \%)$ in hypoxia (Fig. $3, A$ and $B$ ). The elevation in $\mathrm{CO}$ 

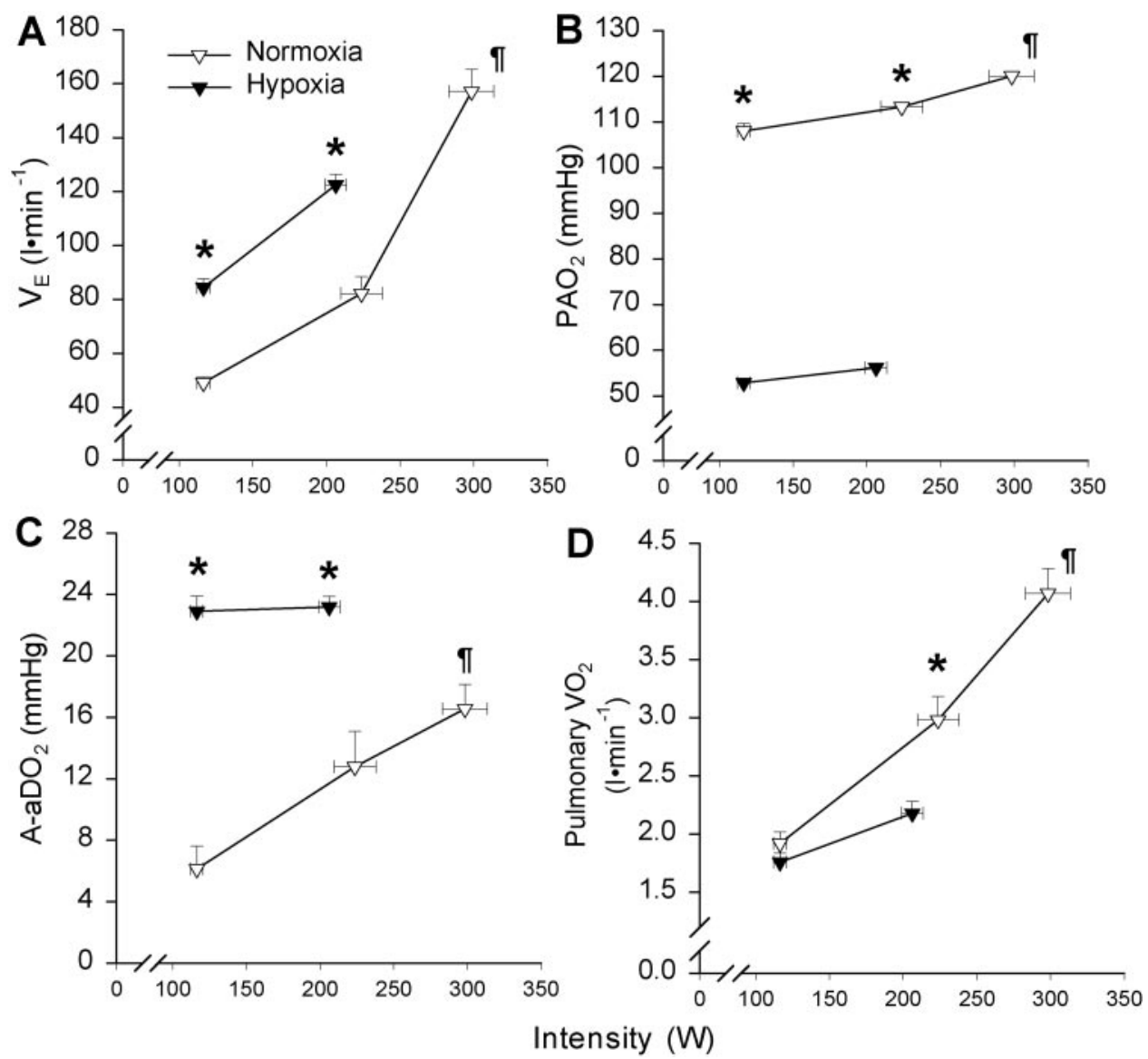

Fig. 2. Pulmonary ventilation $(\dot{\mathrm{V}} \mathrm{E})$ and gas exchange. $\dot{\mathrm{V}}$, alveolar $\mathrm{PO}_{2}\left(\mathrm{~Pa}_{2}\right)$, alveolar-arterial $\mathrm{O}_{2}$ difference (A$\mathrm{aDO}_{2}$ ), and whole body oxygen uptake $\left(\mathrm{V}_{2}\right)$ during submaximal and maximal exercise with normoxia $(\nabla)$ and hypoxia $(\boldsymbol{\nabla})$. * Significant differences between normoxia and hypoxia at the same absolute exercise intensity $(P<0.05)$. When maximal exercise values are compared, II indicates significant differences between normoxia and hypoxia $(P<0.05)$.

was brought about by an increase in HR from $132 \pm 6$ to $158 \pm 4$ beats/min $(P<0.001)$, whereas stroke volume (SV) was similar in normoxia and hypoxia (Fig. $3, C$ and $E$ ). Inasmuch as MAP was similar in both conditions, the additional increase in systemic and LBF observed during hypoxia was achieved entirely through 18 and $20 \%$ enhancements of systemic and leg vascular conductances, respectively (Fig. $3, D, F$, and $G)$. The increase in blood flow, however, was insufficient to offset the reduction in $\mathrm{Ca}_{\mathrm{O}_{2}}$, and, as a consequence, both systemic and leg $\mathrm{O}_{2}$ delivery fell with hypoxia by 22 and $25 \%$, respectively (Fig. $4, A$ and $B$ ). As expected, leg lactate and proton release were dramatically increased with hypoxia (from $0.05 \pm 0.25$ to $3.01 \pm 0.83 \mathrm{mmol} / \mathrm{min}$ and from $3.44 \pm 1.53$ to $5.97 \pm$ $0.89 \mathrm{mmol} / \mathrm{min}$, respectively) inducing a marked lactic acidosis (Table 1) that likely contributed to the observed $15 \%$ increase in $\mathrm{O}_{2}$ extraction and the reduced amount of $\mathrm{O}_{2}$ left in femoral venous blood during hypoxia (Fig. $4, D$ and $E$ ). In fact, a significant inverse relationship was found between arterial $\mathrm{pH}$ and leg $\mathrm{O}_{2}$ extraction during hypoxia $(r=-0.70, P<0.05)$.

Arterial and venous plasma norepinephrine concentrations were markedly elevated in acute hypoxia compared with normoxia. However, arterial and venous plasma epinephrine concentrations were similar in the two conditions (Fig. 5).

Maximal exercise. Maximal exercise capacity was substantially reduced with acute hypoxia. $\mathrm{V}_{2}$ max de- creased by $47 \%$ (from $4.10 \pm 0.25$ to $2.18 \pm 0.10 \mathrm{l} / \mathrm{min}$ ) (Fig. 2D) and Wmax by $31 \%$ (from $298 \pm 15$ to $206 \pm 7$ W). Peak exercise $\dot{V} E$ was lower in hypoxia than in normoxia (122 \pm 4 vs. $157 \pm 8 \mathrm{l} / \mathrm{min}$ ) (Fig. $2 A$ ) and the corresponding arterial plasma $\mathrm{K}^{+}$as well $(5.6 \pm 0.1$ and $6.0 \pm 0.1 \mathrm{meq} / \mathrm{l})$. However, the arterial $\mathrm{pH}$ was higher and the arterial $\mathrm{PCO}_{2}$ was lower in hypoxia than in normoxia (Table 1). The latter combined with the higher $\dot{\mathrm{V}} \mathrm{E} / \dot{\mathrm{V}}_{2}(57 \pm 2$ vs. $39 \pm 1)$ and $\dot{\mathrm{V}} \mathrm{E} / \dot{\mathrm{V}}_{\mathrm{CO}_{2}}(40 \pm 1$ vs. $33 \pm 1$ ) in ratio in hypoxia indicates a relatively greater hyperventilatory response to maximal exercise in hypoxia. However, as illustrated in Fig. $2 C$, maximal exercise $\mathrm{A}-\mathrm{aDO}_{2}$ was higher in hypoxia than in normoxia $(23.2 \pm 0.7$ vs. $16.6 \pm 1.6 \mathrm{mmHg}, P<0.001)$ and was related to the $\mathrm{Pa}_{\mathrm{O}_{2}}$ in normoxia $(r=-0.95, P<$ $0.001)$ and hypoxia $(r=-0.80, P<0.01)$.

Peak CO and LBF were reduced by 17 and $22 \%$, respectively, during acute hypoxia. The diminution in peak $\mathrm{CO}$ with hypoxia was due to the combined reductions in peak HR (8\%) and SV (9\%) (Fig. 3, A, C, and D). $\mathrm{CO}, \mathrm{LBF}, \mathrm{HR}$, and $\mathrm{SV}$ attained at exhaustion during hypoxia were all similar to those observed at the same absolute exercise intensity during normoxia (Fig. 3, $A-C$, and $E$ ). In hypoxia, MAP was lower than duringnormoxia both at exhaustion and at the same absolute work intensity at which exhaustion occurred during the hypoxic trial (Fig. 3D).

At maximal exercise, systemic and two-leg vascular conductance was reduced. However, at the absolute 
Fig. 3. Cardiovascular variables. Cardiac output $(\dot{Q})$, stroke volume $(\mathrm{SV})$, heart rate (HR), 2-leg blood flow (2$\mathrm{LBF})$, mean arterial pressure (MAP), systemic vascular conductance (VC), and 2-leg VC during submaximal and maximal exercise with normoxia $(\nabla)$ and hypoxia $(\mathbf{v})$. * Significant differences between normoxia and hypoxia at the same absolute exercise intensity $(P<0.05)$. When maximal exercise values are compared, II indicates significant differences between normoxia and hypoxia $(P<0.05)$.
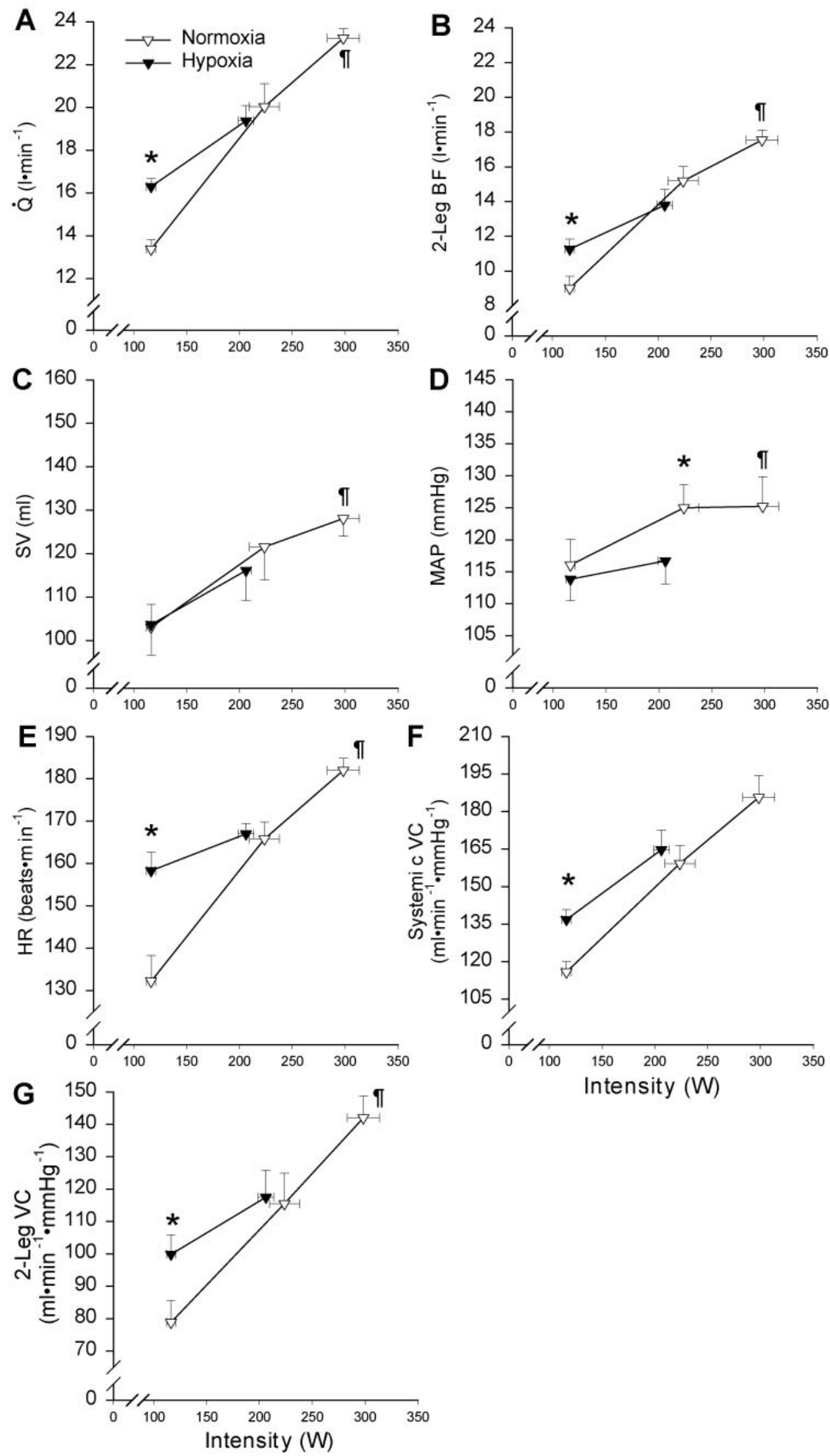

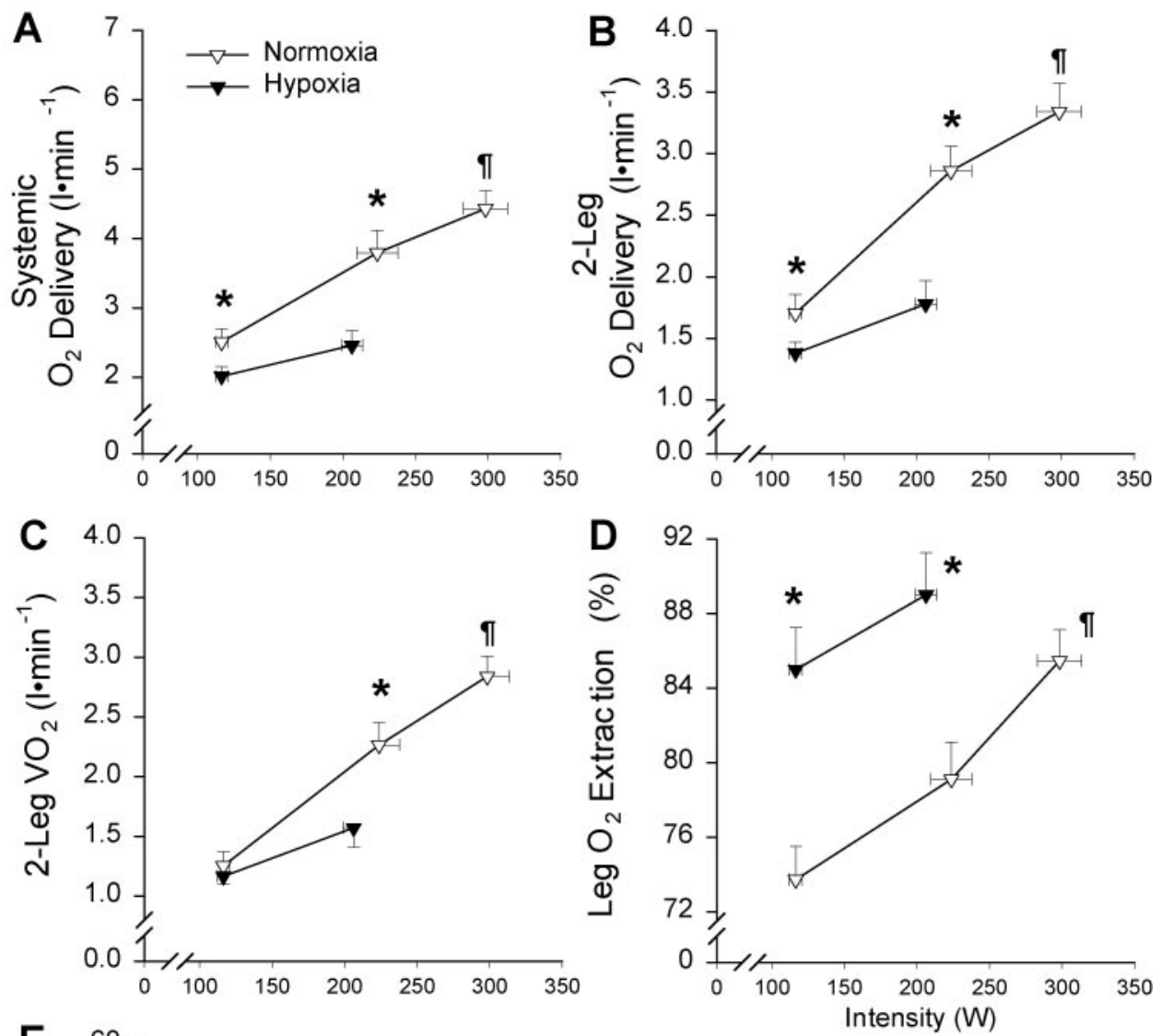

Fig. 4. Oxygen transport and $\mathrm{O}_{2}$ consumption. Systemic $\mathrm{O}_{2}$ delivery, 2-leg $\mathrm{O}_{2}$ delivery, femoral $\mathrm{O}_{2}$ content arteriovenous difference (a-vO $\mathrm{v}_{2}$ diff), whole body $\mathrm{O}_{2}$ uptake (pulmonary $\mathrm{VO}_{2}$ ), 2-leg $\mathrm{O}_{2}$ uptake (2-Leg $\left.\dot{\mathrm{V}}_{2}\right)$, leg $\mathrm{O}_{2}$ extraction and $\mathrm{O}_{2}$ content of the femoral venous blood $\left(\mathrm{C}_{\mathrm{fv}} \mathrm{O}_{2}\right)$ during submaximal and maximal exercise with normoxia $(\nabla)$ and hypoxia $(\boldsymbol{\nabla}) . *$ Significant differences between normoxia and hypoxia at the same absolute exercise intensity $(P<0.05)$. When maximal exercise values are compared, II indicates significant differences between normoxia and hypoxia $(P<0.05)$.

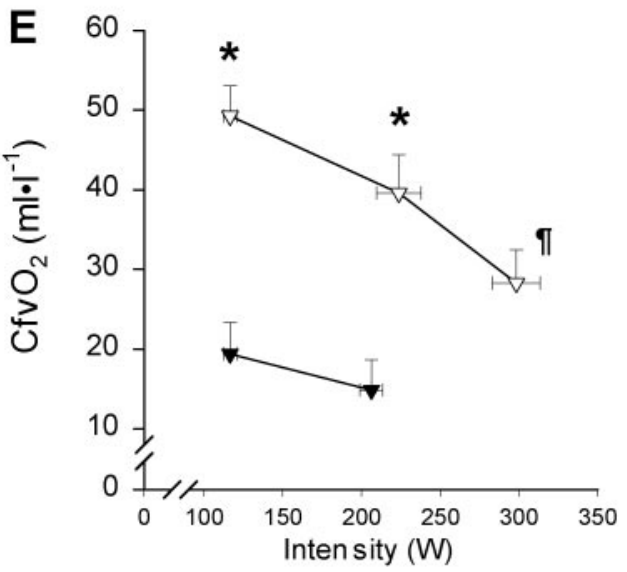

load equal to the maximal load reached in hypoxia, vascular conductances were similar in hypoxia and normoxia (Fig. $3, F$ and $G$ ).

The combined decreases in peak blood flow and $\mathrm{Ca}_{2}$ during hypoxia significantly reduced systemic and twoleg $\mathrm{O}_{2}$ delivery (Fig. 4, $A$ and $B$ ). This reduction in $\mathrm{O}_{2}$ delivery was only partially offset by a $4 \%$ increase in $\mathrm{O}_{2}$ extraction (Fig. 4D). Accordingly, peak whole body (pulmonary) and leg $\mathrm{V}_{2}$ were reduced by 47 and $45 \%$, respectively (Fig. $2 D$ and $4 C$ ). No significant differences were observed between hypoxia and normoxia for non-leg $\dot{\mathrm{V}}_{2}$.

Similar two-leg lactate and proton release were observed in both conditions. Arterial and venous plasma norepinephrine concentrations were elevated similarly in acute hypoxia and normoxia at Wmax, as were those for epinephrine (Fig. 5). By contrast, at a similar absolute load in normoxia at which the maximal effort was reached in hypoxia, arterial and venous plasma catecholamine concentrations were three to six times lower (Fig. 5).

\section{Distribution of CO During Submaximal and Maximal Exercise}

A similar proportion of $\mathrm{CO}$ was directed to the exercising legs during submaximal $(70 \pm 5$ and $68 \pm 5 \%)$ and maximal exercise $(71 \pm 4$ and $76 \pm 2 \%)$ in hypoxia 

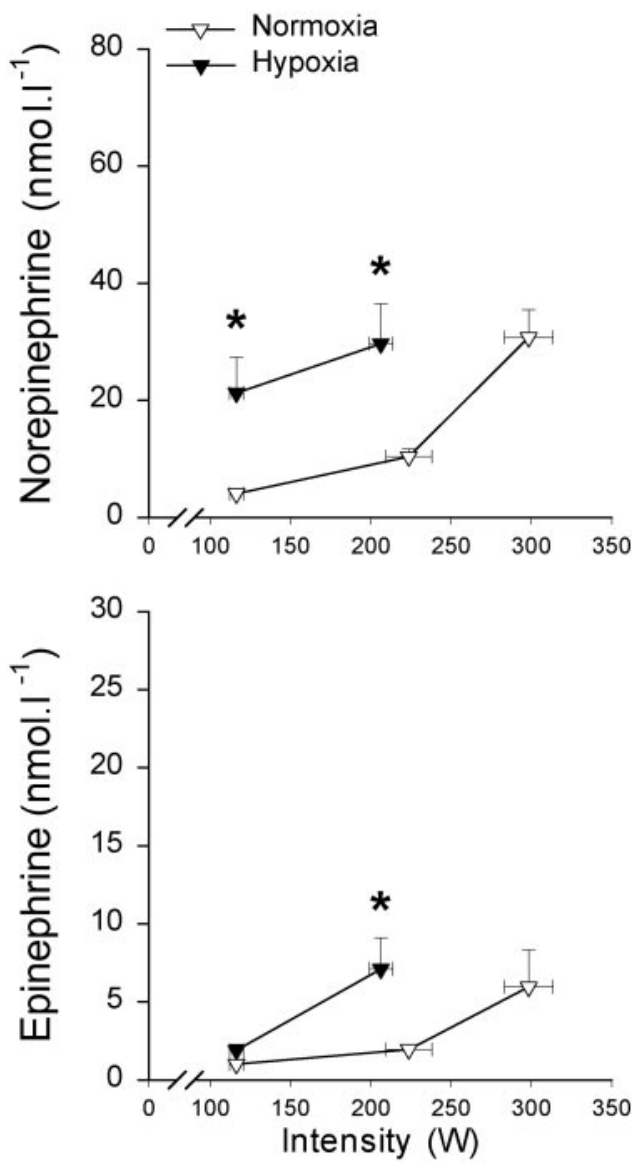

Fig. 5. Plasma catecholamines. Arterial plasma norepinephrine (top) and epinephrine (bottom) concentrations during submaximal and maximal exercise with normoxia $(\nabla)$ and hypoxia $(\mathbf{\nabla}) .{ }^{*}$ Significant differences between normoxia and hypoxia at the same absolute exercise intensity $(P<0.05)$.

and normoxia. Accordingly, the magnitude of the blood flow distributed to other vascular beds (non-LBF) was comparable during submaximal $(5.0 \pm 0.8$ and $4.4 \pm$ $0.6 \mathrm{l} / \mathrm{min})$ and maximal exercise $(5.7 \pm 0.9$ and $5.7 \pm$ $0.6 \mathrm{l} / \mathrm{min}$ ) in hypoxia and normoxia. The lumped vascular conductance through tissues other than the legs (non-leg vascular conductance) was also similar during submaximal ( $46 \pm 6$ and $40 \pm 7 \mathrm{ml} / \mathrm{mmHg}, n=7)$ and maximal exercise ( $49 \pm 8$ and $45 \pm 5 \mathrm{ml} / \mathrm{mmHg}, n=7$ ) in hypoxia and normoxia.

In normoxia, $\mathrm{CO}$ was closely related to exercise intensity $(r=0.84, P<0.001)$, as was LBF $(r=0.77, P<$ 0.01 ), whereas no relationship was observed between either CO or LBF and exercise intensity in hypoxia. As depicted in Fig. 6, there were close linear relationships between mean leg $\dot{\mathrm{V}}_{2}$ and the mean leg $\mathrm{O}_{2}$ delivery during submaximal $(r=0.98, r=0.95, P<0.001)$ and maximal exercise $(r=0.94, r=0.97, P<0.001)$ in normoxia and hypoxia, respectively.

\section{Hypoxia to Normoxia Transition at Wmax}

Immediately before exhaustion at the hypoxic Wmax, seven subjects were asked to keep pedaling while they were switched to breathing room air (nor- moxia). During the first $10-20 \mathrm{~s}$, exercise intensity declined slightly. However, after this transient phase, they could reach the target pedaling rate and the test was continued by increasing the load by $20-40 \mathrm{~W} / \mathrm{min}$ until exhaustion as performed during the control incremental exercise in normoxia. At exhaustion, the intensity was $9 \%$ lower $(P<0.05)$ than that attained in the control incremental exercise with normoxia. Despite this decrease in intensity, the values for $\mathrm{CO}, \mathrm{LBF}, \mathrm{HR}$, $\mathrm{SV}$, leg and systemic vascular conductance, leg $\mathrm{O}_{2}$ delivery, leg fractional extraction of $\mathrm{O}_{2}$, and leg $\dot{\mathrm{V}}_{2}$ were identical to those obtained at exhaustion during the control incremental exercise with normoxia.

\section{DISCUSSION}

The novel finding of this study was that a substantial proportion of the $\sim 50 \%$ reduction of $\dot{\mathrm{V}}_{2}$ max in acute severe hypoxia is attributed to a lower maximal $\mathrm{CO}$ and muscle blood flow. Previously, it has been shown that with more moderate acute hypoxia equivalent to an altitude of $\sim 4,000 \mathrm{~m}, \mathrm{CO}$ at maximal exercise is
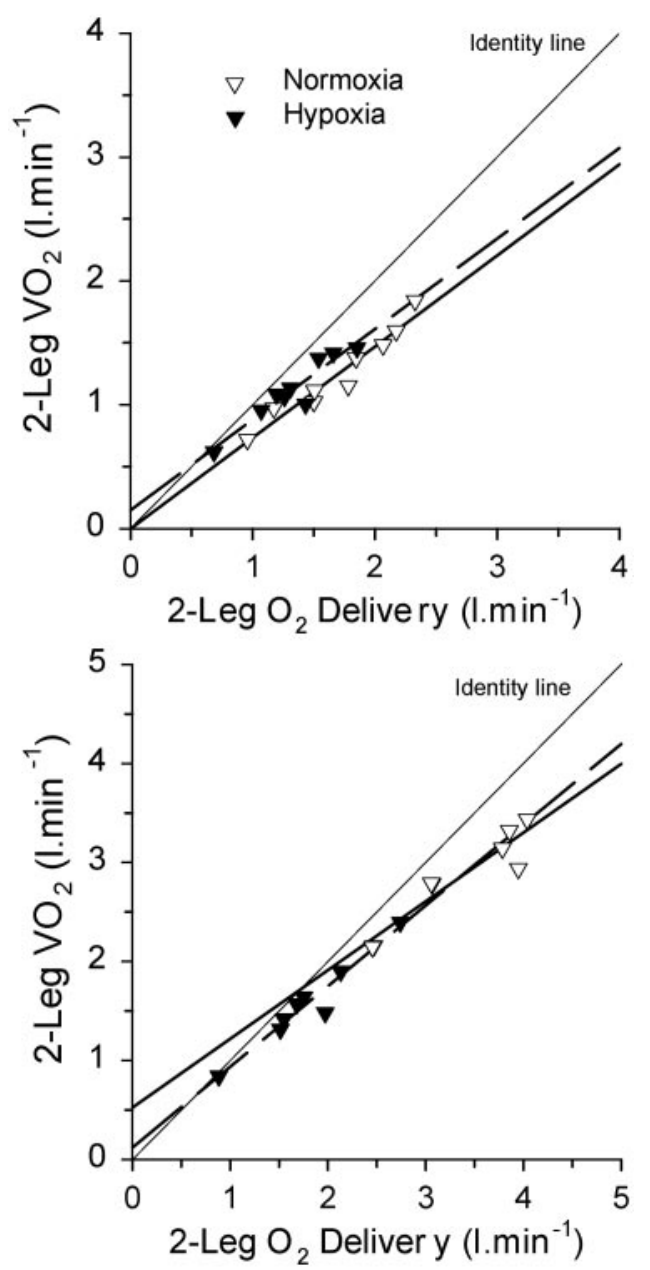

Fig. 6. Relationship between $\mathrm{O}_{2}$ uptake and delivery. Relationship between 2-leg $\dot{\mathrm{VO}}_{2}$ and 2-leg $\mathrm{O}_{2}$ delivery during submaximal (top) and maximal (bottom) exercise with normoxia ( $\nabla$; continuous line) and hypoxia ( $\mathbf{v}$; dashed line). Note that the regression lines obtained in normoxia and hypoxia were similar suggesting that $\dot{\mathrm{V}}_{2}$ depends on $\mathrm{O}_{2}$ delivery. 
essentially similar to that at sea level (Table 2) (44). Thus, this study identifies a mechanism whereby $\mathrm{VO}_{2}$ max in severe hypoxia is attenuated in excess of what previously was explained by the fall in arterial $\mathrm{O}_{2}$ saturation and content (19). Our results show that although two-thirds of the reduction of $\mathrm{V}_{2}$ max in acute severe hypoxia are accounted for by the fall in $\mathrm{O}_{2}$ content, one-third of the reduction is due to a decrease in peak $\mathrm{CO}$ and muscle blood flow. It should be emphasized that we observed a close relationship between leg maximal $\mathrm{O}_{2}$ delivery and leg $\mathrm{V}_{2}$ max, regardless of $\mathrm{FI}_{\mathrm{O}_{2}}$, which supports the concept that during exercise with a large muscle mass, $\dot{\mathrm{V}}_{2}$ max is limited largely by $\mathrm{O}_{2}$ supply $(7,44)$. Furthermore, the lack of a significant alteration in the fractional distribution of blood flow between the locomotor skeletal muscles and the upper body tissues suggests that $\mathrm{CO}$ is the primary determinant of LBF during maximal exercise in normoxia, as well as in acute severe hypoxia.

\section{Attainment of Maximal Effort}

In acute hypoxia, as well as in normoxia, the data suggest that subjects exercised to their limit since 1) similar high levels of arterial and femoral venous lactate were reached at exhaustion in normoxia and hypoxia, 2) femoral venous $\mathrm{O}_{2}$ tensions at maximal exercise with hypoxia were among the lowest reported for upright cycling exercise $(6-14 \mathrm{mmHg})(7,44), 3)$ the rating of perceived exertion was maximal in hypoxia and normoxia, 4) all tests were performed to exhaustion through vigorous verbal encouragement, and 5) all subjects had previously participated in high-altitude studies and were very familiar with all the procedures.

\section{Effect of Severe Acute Hypoxia on Maximal CO}

The mechanism responsible for the reduction in peak CO in severe acute hypoxia appears to be linked to low $\mathrm{Pa}_{\mathrm{O}_{2}}$. The reduction in $\mathrm{CO}$ experienced with severe acute hypoxia could be envisaged as a regulatory mechanism aimed at protecting either the heart itself or, more importantly, the CNS from hypoxic damage (38) due to the risk of increased desaturation at very high CO. Alternatively, hypoxia could limit the intrinsic pumping capacity of the heart and/or alter neuroendocrine regulation of vascular tone affecting preload or afterload (i.e., a change in conductance in different areas throughout the vascular system). A downregulation of maximal CO in acute hypoxia is supported by the fact that, at fatigue, $\mathrm{Pa}_{\mathrm{O}_{2}}$ and arterial hemoglobin saturation were very similar in all subjects.

Desaturation in well-trained athletes during maximal exercise at sea level has been associated with, among other factors, a very high CO (13). Due to the sigmoid shape of the $\mathrm{O}_{2}$ dissociation curve of hemoglobin, a minimal reduction of lung mean transit time during hypoxia when arterial $\mathrm{O}_{2}$ saturation lies on the steep position of the $\mathrm{O}_{2}$ dissociation curve, as occurred during maximal exercise in hypoxia $\left(66 \% \mathrm{Sa}_{\mathrm{O}_{2}}\right)$, could cause a substantial decrease of $\mathrm{Pa}_{\mathrm{O}_{2}}$ and $\mathrm{Sa}_{\mathrm{O}_{2}}$ (26). It has been shown that lung mean transit time is reduced as $\mathrm{CO}$ increases $(22,26)$. Under these circumstances, a further elevation in $\mathrm{CO}$ might result in no increase or, even worse, a deterioration of systemic $\mathrm{O}_{2}$ supply. If this hypothesis is true, maximal $\mathrm{O}_{2}$ delivery in acute hypoxia will be attained at a lower maximal CO than in normoxia. The downregulation of maximal $\mathrm{CO}$ was likely mediated by $\mathrm{Pa}_{2}$ and presumably $\mathrm{Ca}_{\mathrm{O}_{2}}$ - and $\mathrm{Sa}_{\mathrm{O}_{2}}$-sensing mechanisms that adjust the output drive from cardiovascular nuclei in the CNS. At peak exercise with hypoxia, $\mathrm{Pa}_{\mathrm{O}_{2}}$ reached $34 \mathrm{mmHg}$.

Hypoxia can be sensed directly by sympathoexcitatory reticulospinal vasomotor neurons of the rostral ventrolateral reticular nucleus of the medulla (45), which initiate the integrated response to hypoxia by activating neurons distributed elsewhere in the CNS. Consequently, sympathetic nerve activity and arterial blood pressure are elevated and HR depressed by CNS hypoxia (12). The cardioinhibitory effect of hypoxia could have been also mediated by activation of the peripheral chemoreceptors, which, through the release of nitric oxide, may attenuate the activation of presympathetic vasomotor neurons at the rostral ventrolateral medulla during hypoxia (50).

This study shows a lower maximal HR during exercise in hypoxia, which could have been mediated by stimulation of medullary cardiovagal neurons by the

Table 2. Systemic $\mathrm{O}_{2}$ transport and gas exchange at maximal exercise measured during upright cycling with acute hypoxia equivalent to an altitude of 4,000 $\mathrm{m}$ (Stenberg et al., Ref. 44) and at 5,300 m (present study)

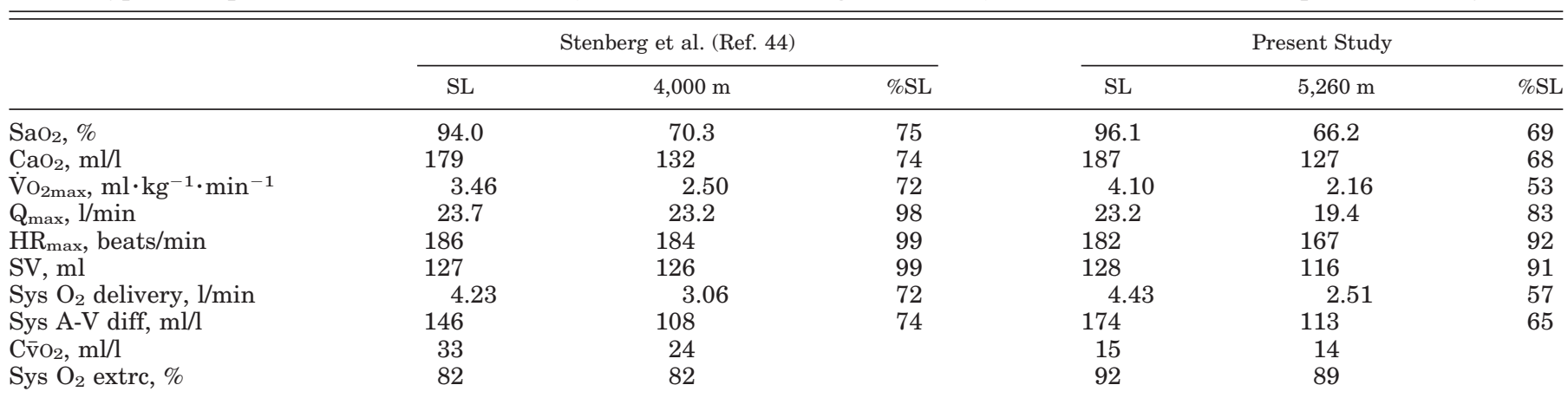

$\mathrm{SaO}_{2}, \mathrm{O}_{2}$ saturation; Q, cardiac output; HR, heart rate; SV, stroke volume; Sys, systemic; A-Vdiff, arteriovenous difference; $\mathrm{C} \overline{\mathrm{v}} \mathrm{O}_{2}$, venous $\mathrm{O}_{2}$ content in mixed blood; extrc, $\mathrm{O}_{2}$ extraction; SL, sea level. 
low $\mathrm{PO}_{2}$ values attained at exhaustion (40). In fact, in chronic hypoxia, maximal HR is substantially decreased but it can be restored to normoxic values by vagal blockade with glycopyrrolate (10). In addition, this study shows that during maximal upright exercise in acute severe hypoxia, maximal SV is also reduced. The reason why SV was diminished at maximal exercise in acute hypoxia despite a small reduction in afterload is not clear. Two mechanisms, however, could explain this phenomenon: an impairment of myocardial contractile function and/or lower preload caused by a reduction in venous return.

There were no indications in the present study to suggest an intrinsic impairment of the pumping capacity of the heart or a failure in neuroendocrine regulation of regional compliances at maximal exercise in hypoxia. All subjects tolerated well the exercise tests and showed no unusual patterns in ECG or blood pressure responses. The adrenergic response to maximal exercise in the present study was similar in hypoxia and normoxia as previously reported $(28,39)$, indicating a similar positive inotropic stimulation and presumably a similar sympathetic vasoconstrictor drive at maximal exercise in acute hypoxia and normoxia. Even though a reduced myocardial contractility in hypoxia cannot be ruled out completely, impairment of left ventricular function has not been reported during maximal exercise at even higher levels of hypoxia than in the present study $(28,37)$. Parallel studies in which the same subjects exercised in acute hypoxia showed that the myocardium is capable of maintaining aerobic metabolism at even greater simulated altitude (27). Moreover, at the end of the exercise with hypoxia when seven subjects were switched to breathing room air, all of them were able to reach their maximal CO. The fact that maximal $\mathrm{CO}$ in hypoxia was rapidly enhanced by simply increasing the $\mathrm{FI}_{\mathrm{O}_{2}}$ to 0.21 suggests that reoxygenation either of the heart itself or of the CNS influences peak CO. In contrast, the fact that it was possible to continue the incremental exercise test with reoxygenation argues against a peripheral (muscular or metabolic) mechanism as the main cause of fatigue in severe acute hypoxia (25).

An alternative explanation for the decrease of maximal CO with acute hypoxia is an impairment of venous return and, hence, ventricular filling pressure. Several factors may influence venous return during exercise, such as central blood volume, body posture, cardiac aspirating effects, venous vascular tone (venous capacitance), MAP, the muscle pump, the respiratory pump, and $\mathrm{CO}$ itself (25). At maximal exercise during hypoxia in the present study, the action of the respiratory and muscle pumps likely attenuated. In normoxia, a close relationship was observed between maximal $\mathrm{CO}$ and maximal exercise intensity. The action of the muscle pump increases with exercise intensity and exerts an important influence on venous return and $\mathrm{CO}(8,14,25,42)$. One possibility is that muscular fatigue during exercise with hypoxia curtails increases in power output, which, in turn, would limit the action of the muscle pump and ventricular filling.
However, it is more likely that hypoxia first attenuates increases in CO that limits muscle oxygen delivery and power output and, in turn, the muscle pump and ventricular filling. In hypoxia, the mean values for $\mathrm{CO}$ and LBF at exhaustion were identical to those obtained at the same absolute intensity during normoxia.

\section{Effect of Severe Acute Hypoxia on Maximal LBF}

Despite a considerable body of research, the mechanisms that regulate maximal skeletal muscle blood flow during exercise remain elusive. Pioneer investigators showed that alterations in $\mathrm{Ca}_{\mathrm{O}_{2}}$ induced by breathing hypoxic-hyperoxic gases or carbon monoxide, or by blood withdrawal or transfusion, are counterbalanced by changes in $\mathrm{CO}$, so that systemic $\mathrm{O}_{2}$ delivery is maintained during submaximal exercise $(6,16,21)$. Likewise, $\mathrm{LBF}$ can be increased to compensate for a reduction in $\mathrm{Ca}_{\mathrm{O}_{2}}$ elicited by acute hypoxia $(29,30,41)$. Our results showing an increase in $\mathrm{CO}$ and LBF during submaximal exercise with acute hypoxia are in full agreement with these earlier studies. On the other hand, in contrast to Knight et al. (29), who reported similar LBFs during maximal upright cycling exercise in normoxia and hypoxia, we observed a significant reduction in maximal $\mathrm{LBF}$ in acute hypoxia that closely followed the decrease in maximal CO. This apparent discrepancy is likely due to the more severe hypoxia induced in the present study. Although Knight et al. (29) used a $\mathrm{FI}_{\mathrm{O}_{2}}$ of 0.12 , which elicited a $\mathrm{Pa}_{\mathrm{O}_{2}}$ of 42 $\mathrm{mmHg}$ at exhaustion, we used a $\mathrm{F}_{\mathrm{O}_{2}}$ of 0.105 , which elicited a lower $\mathrm{Pa}_{\mathrm{O}_{2}}(34 \mathrm{mmHg})$ at exhaustion.

Although the mechanisms that regulate peak LBF during maximal exercise remain unclear, some experimental evidence points to the existence of a tight coupling between maximal $\mathrm{CO}$ and peak muscle blood flow during exhaustive exercise $(5,32,35)$. For example, Pawelczyk et al. (35) reported a reduction of both $\mathrm{CO}$ and LBF during maximal cycling exercise with $\beta$-blockade. Likewise, in patients with chronic heart failure, Magnusson et al. (32) observed a decrease in peak muscle blood flow during two-leg extension exercise but not during one-leg extension exercise, suggesting that when maximal pumping capacity of the heart was diminished, peak muscle blood flow was reduced. The present study adds further evidence along this line and demonstrates for the first time that in severe acute hypoxia with a large muscle mass, peak LBF is reduced by an amount equal to the drop in maximal $\mathrm{CO}$. The latter implies that the amount of blood flow to upper body tissues was similar in normoxia and hypoxia, indicating that a lowered maximal CO cannot be compensated for by redistributing a greater proportion of blood to the active muscles at the expense of reducing blood flow to noncontracting tissues in severe acute hypoxia.

\section{Effect of Severe Acute Hypoxia on Pulmonary Gas Exchange}

Pulmonary gas exchange was dramatically impaired during exercise in hypoxia lowering the $\mathrm{Pa}_{\mathrm{O}_{2}}$ from 47 at 


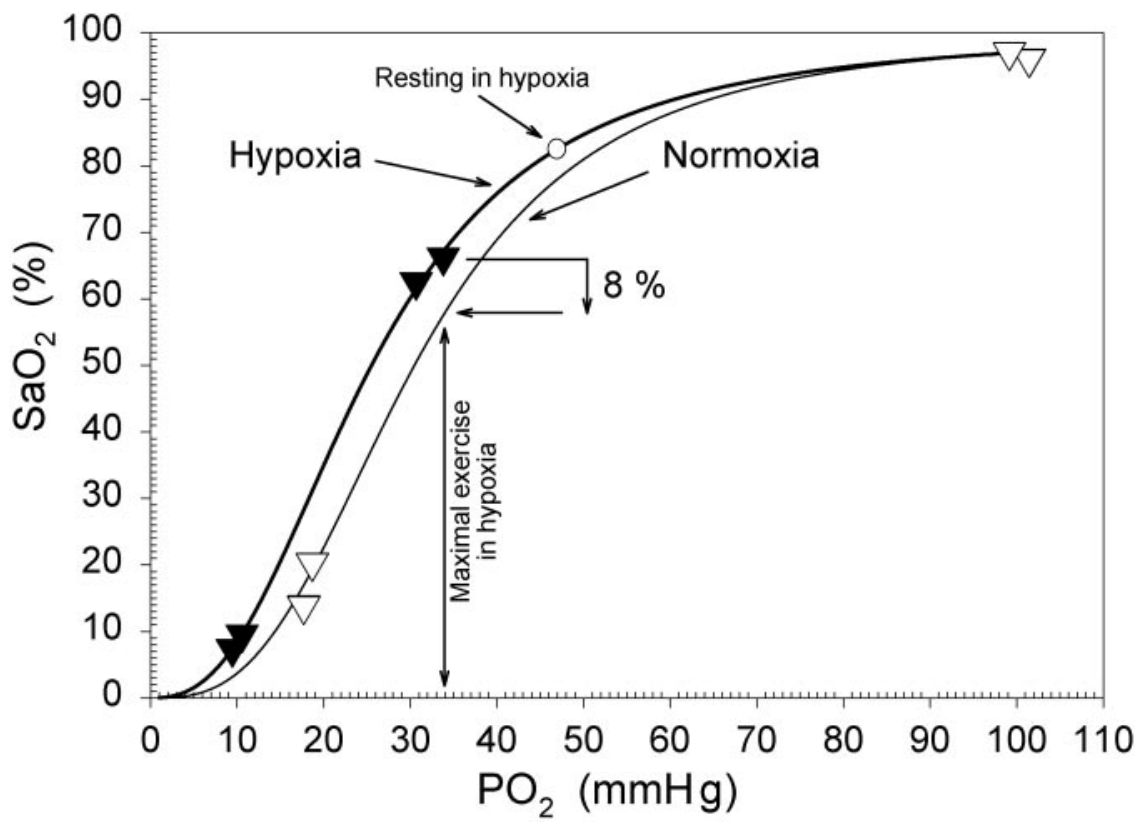

Fig. 7. Hemoglobin dissociation curve. Effect of acute hypoxia on the $\mathrm{O}_{2}$ dissociation curve of the hemoglobin during exercise in normoxia ( $\nabla$; fine line) and hypoxia ( $\mathbf{v}$; thick line). Note the left shift caused by hyperventilation and its impact on $\mathrm{Sa}_{2}$ at maximal exercise in hypoxia. Points in the graph represent the mean arterial or femoral venous values for each condition. $\left(\mathrm{PO}_{2}\right.$ values corrected for blood temperature.) rest to $34 \mathrm{mmHg}$ at maximal exercise and the corresponding $\mathrm{Sa}_{\mathrm{O}_{2}}$ from 82 to $66 \%$. Alveolar $\mathrm{Po}_{2}$ during maximal exercise in normoxia was $120 \mathrm{mmHg}$, which, in case of a perfect pulmonary gas exchange $\left(\mathrm{A}-\mathrm{aDO}_{2}=\right.$ 0 ), would have elicited $\mathrm{a} \mathrm{SaO}_{2}$ of $98 \%$. In the same conditions, an alveolar $\mathrm{Po}_{2}$ of $56 \mathrm{mmHg}$, as that observed at exhaustion in acute hypoxia, would have corresponded to a $\mathrm{Sa}_{\mathrm{O}_{2}}$ of $86 \%$. Therefore, $41 \%$ of the reduction in $\mathrm{Ca}_{2}$ during maximal exercise in acute hypoxia could be explained by the lower $\mathrm{PI}_{\mathrm{O}_{2}}$ and $59 \%$ by the impairment of pulmonary gas exchange. The drop in $\mathrm{Sa}_{\mathrm{O}_{2}}$ with hypoxia occurred despite substantial hyperventilation, which allowed for an elevation of $\mathrm{Pa}_{\mathrm{O}_{2}}$ (by $8 \mathrm{mmHg}$ ) from rest to maximal exercise. This level of hyperventilation had a dramatic effect on blood $\mathrm{pH}$, which was 0.1 units higher at exhaustion in hypoxia than in normoxia. The impact of hyperventilation on $\mathrm{Sa}_{2}$ at maximal exercise in hypoxia is well illustrated in Fig. 7. With a higher $\mathrm{pH}$, the hemoglobin $\mathrm{O}_{2}$ dissociation curve was shifted to the left in hypoxia, improving the level of $\mathrm{Sa}_{\mathrm{O}_{2}}$ for a given $\mathrm{Pa}_{\mathrm{O}_{2}}$ (Fig. 7). Applying the Hill's equation for $\mathrm{O}_{2}$ saturation of hemoglobin, we calculated that had the arterial $\mathrm{pH}$ during maximal exercise in hypoxia been similar to that attained in normoxia the $\mathrm{Sa}_{\mathrm{O}_{2}}$ would have only been $58 \%$, i.e., $8 \%$ less than actually observed (Fig. 7). However, maximal ventilation was $22 \%$ lower during maximal exercise in hypoxia, perhaps owing to excessive elimination of $\mathrm{CO}_{2}$, as corroborated by the low $\mathrm{Pa}_{\mathrm{CO}_{2}}$ and high $\mathrm{pH}$ observed at exhaustion, despite similar arterial blood lactate concentrations in normoxia and hypoxia (33). The lower arterial plasma $\mathrm{K}^{+}$concentration reached in hypoxia could have also attenuated the ventilatory drive in this condition (34). Given the sigmoid shape of the hemoglobin $\mathrm{O}_{2}$ dissociation curve, had the ventilatory response in hypoxia been similar to that in normoxia, then a small additional enhancement of $\mathrm{Pa}_{\mathrm{O}_{2}}$ would have been possible and likely, a greater $\mathrm{Sa}_{\mathrm{O}_{2}}$ would have been reached in hypoxia.

The widening of the $\mathrm{A}-\mathrm{aDO}_{2}$ reflects a lower efficiency of the gas exchange process in hypoxia than in normoxia, as supported by the close relationship observed between $\mathrm{A}-\mathrm{aDO}_{2}$ and $\mathrm{Pa}_{2}$ in both conditions. According to the model of Piiper and Scheid (36), the process of gas exchange by diffusion in a homogeneous lung can be described by the equation $(\mathrm{Pa}-\mathrm{Pv}) /(\mathrm{PA}-$ $\mathrm{Pv})=1-\exp (-\mathrm{D} / \beta \dot{\mathrm{Q}})$, where $\mathrm{Pa}$ is arterial $\mathrm{Po}_{2}, \mathrm{Pv}$ is mixed venous $\mathrm{Po}_{2}, \mathrm{PA}$ is alveolar $\mathrm{Po}_{2}, \mathrm{D}$ is $\mathrm{O}_{2}$ pulmonary diffusing capacity, $\beta$ is effective solubility coefficient of $\mathrm{O}_{2}$ in blood (essentially the average slope of the $\mathrm{O}_{2}$ hemoglobin dissociation curve), and $\mathrm{Q}$ is CO. A high $\mathrm{CO}$ decreases the mean transit time across the alveolar capillaries (22) and could be one of the factors explaining the increase of $\mathrm{A}-\mathrm{aOD}_{2}$ with exercise intensity in both conditions, due to the reduction of the time available for diffusive equilibration. At maximal exercise, CO was lower in hypoxia and, thus per se, could not contribute to reducing the ratio of $\mathrm{D} /(\beta \dot{\mathrm{Q}})$ compared with normoxia. Because $\beta$ was increased with hypoxia due to the lower $\mathrm{Pa}_{\mathrm{O}_{2}}$, which confined gas exchange to the steep region of the $\mathrm{O}_{2}$ hemoglobin dissociation curve, the impact of diffusion limitation on pulmonary gas exchange was probably considerable at the level of hypoxia used in the present study, where $\mathrm{Pa}_{2}$ fell below $50 \mathrm{mmHg}$ (48). This is consistent with other results $(18,46-48)$. Ventilation mismatch, on the other hand, does not play a major role in severe hypoxia (48).

In summary, during maximal exercise with a large muscle mass in severe acute hypoxia simulating an altitude $\sim 5,300 \mathrm{~m}, \dot{\mathrm{V}}_{2}$ max is reduced by $\sim 50 \%$. Although at moderate altitudes the drop in $\dot{\mathrm{V}}_{\mathrm{O}_{2}}$ max can be explained entirely by the reduction of arterial $\mathrm{O}_{2}$ content, this factor only accounts for about two-thirds of the loss in $\dot{\mathrm{V}}_{2}$ max during maximal exercise with 
severe acute hypoxia. In addition, this study shows that three main mechanisms account for the reduction of $\dot{\mathrm{V}}_{2}$ max in severe acute hypoxia: 1) the reduction of $\mathrm{PI}_{\mathrm{O}_{2}}$, 2) the impairment of pulmonary gas exchange, each explaining about one-half of the drop in arterial $\mathrm{O}_{2}$ content, and 3) the reduction of maximal $\mathrm{CO}$, with a corresponding decrease in peak $\mathrm{LBF}$, explaining the remaining one-third of the loss in $\dot{\mathrm{V}}_{2}$ max. The reduction of maximal $\mathrm{CO}$ with severe acute hypoxia appears to be dependent on the level of hypoxemia, regardless of arterial $\mathrm{O}_{2}$ content. Taken together, these results highlight the importance of $\mathrm{O}_{2}$ delivery as a limiting factor for $\dot{\mathrm{V}}_{2}$ max both in normoxia and hypoxia.

Special thanks are given to C. Nielsen, K. Hansen, and B. Jessen for excellent technical assistance and G. Ordway for insightful comments.

This study was supported by a grant from The Danish National Research Foundation (504-14). J. A. L. Calbet was on leave from the Department of Physical Education at the University of Las Palmas de Gran Canaria.

\section{REFERENCES}

1. Adams RP and Welch HG. Oxygen uptake, acid-base status, and performance with varied inspired oxygen fractions. $J$ Appl Physiol 49: 863-868, 1980.

2. American Physiological Society. Guiding principles for research involving animals and human beings. Am J Physiol Regul Integr Comp Physiol 283: R281-R283, 2002.

3. Andersen LB and Haraldsdottir J. Maximal oxygen uptake, maximal voluntary isometric contraction and physical activity in young Danish adults. Eur J Appl Physiol 67: 315-320, 1993.

4. Andersen $\mathbf{P}$ and Saltin B. Maximal perfusion of skeletal muscle in man. J Physiol 366: 233-249, 1985.

5. Asanoi H, Wada O, Miyagi K, Ishizaka S, Kameyama T, Seto H, and Sasayama S. New redistribution index of nutritive blood flow to skeletal muscle during dynamic exercise. Circulation 85: 1457-1463, 1992.

6. Asmussen $\mathbf{E}$ and Nielsen $\mathbf{M}$. The cardiac output in rest and work at low and high oxygen pressures. Acta Physiol Scand 35: 73-83, 1955.

7. Åstrand PO, Cuddy TE, Saltin B, and Stenberg J. Cardiac output during submaximal work. J Appl Physiol 19: 268-274, 1964.

8. Barendsen GJ and van den Berg JW. Venous capacity, venous refill time and the effectiveness of the calf muscle pump in normal subjects. Angiology 35: 163-172, 1984.

9. Bender PR, Groves BM, McCullough RE, McCullough RG, Huang SY, Hamilton AJ, Wagner PD, Cymerman A, and Reeves JT. Oxygen transport to exercising leg in chronic hypoxia. J Appl Physiol 65: 2592-2597, 1988.

10. Boushel R, Calbet JA, Radegran G, Sondergaard H, Wagner PD, and Saltin B. Parasympathetic neural activity accounts for the lowering of exercise heart rate at high altitude. Circulation 104: 1785-1791, 2001.

11. Calbet JA. Oxygen tension and content in the regulation of limb blood flow. Acta Physiol Scand 168: 465-472, 2000.

12. Dampney RA, Kumada M, and Reis DJ. Central neural mechanisms of the cerebral ischemic response. Characterization, effect of brainstem and cranial nerve transections, and simulation by electrical stimulation of restricted regions of medulla oblongata in rabbit. Circ Res 45: 48-62, 1979.

13. Dempsey JA and Wagner PD. Exercise-induced arterial hypoxemia. J Appl Physiol 87: 1997-2006, 1999.

14. Disler DG, Cohen MS, Krebs DE, Roy SH, and Rosenthal DI. Dynamic evaluation of exercising leg muscle in healthy subjects with echo planar MR imaging: work rate and total work determine rate of T2 change. J Magn Reson Imaging 5: 588-593, 1995.
15. Dow P. Estimations of cardiac output and central blood volume by dye dilution. Physiol Rev 36: 77-102, 1956.

16. Ekblom B, Huot R, Stein EM, and Thorstensson AT. Effect of changes in arterial oxygen content on circulation and physical performance. J Appl Physiol 39: 71-75, 1975.

17. Ekblom B, Wilson G, and Astrand PO. Central circulation during exercise after venesection and reinfusion of red blood cells. J Appl Physiol 40: 379-383, 1976.

18. Erickson BK, Seaman J, Kubo K, Hiraga A, Kai M, Yamaya Y, and Wagner PD. Hypoxic helium breathing does not reduce alveolar-arterial $\mathrm{PO}_{2}$ difference in the horse. Respir Physiol 100: 253-260, 1995.

19. Fulco CS, Rock PB, and Cymerman A. Maximal and submaximal exercise performance at altitude. Aviat Space Environ Med 69: 793-801, 1998.

20. Hallman H, Farnebo LO, Hamberger B, and Johnsson G. A sensitive method for the determination of plasma catecholamines using liquid chromatography with electrochemical detection. Life Sci 23: 1049-1052, 1978.

21. Hartley LH, Vogel JA, and Landowne M. Central, femoral, and brachial circulation during exercise in hypoxia. $J$ Appl Physiol 34: 87-90, 1973.

22. Hopkins SR, Belzberg AS, Wiggs BR, and McKenzie DC. Pulmonary transit time and diffusion limitation during heavy exercise in athletes. Respir Physiol 103: 67-73, 1996.

23. Horstman $\mathbf{D}$, Weiskopf $\mathbf{R}$, and Jackson RE. Work capacity during 3 -wk sojourn at 4,300 m: effects of relative polycythemia. J Appl Physiol 49: 311-318, 1980.

24. Hughes RL, Clode M, Edwards RH, Goodwin TJ, and Jones NL. Effect of inspired $\mathrm{O}_{2}$ on cardiopulmonary and metabolic responses to exercise in man. J Appl Physiol 24: 336-347, 1968.

25. Janicki JS, Sheriff DD, Robotham JL, and Wise RA. Cardiac output during exercise: contributions of the cardiac, circulatory and respiratory systems. In: Handbook of Physiology. Exercise: Regulation and Integration of Multiple Systems. Bethesda, MD: Am. Physiol. Soc., 1996, sect. 12, chapt. 15, p. 649-704.

26. Johnson RLJ. Oxygen transport. In: Clinical Cardiology, edited by Willerson JT and Sanders CA. New York: Grune \& Stratton, 1977, p. 74-84.

27. Kaijser L and Roach RC. Myocardial blood flow and oxygen extraction in man after adaptation to high altitude. FASEB $J$ 13: LB57, 1999.

28. Kjaer M, Hanel B, Worm L, Perko G, Lewis SF, Sahlin K, Galbo H, and Secher NH. Cardiovascular and neuroendocrine responses to exercise in hypoxia during impaired neural feedback from muscle. Am J Physiol Regul Integr Comp Physiol 277: R76-R85, 1999.

29. Knight DR, Schaffartzik W, Poole DC, Hogan MC, Bebout DE, and Wagner PD. Effects of hyperoxia on maximal leg $\mathrm{O}_{2}$ supply and utilization in men. J Appl Physiol 75: 2586-2594, 1993.

30. Koskolou MD, Calbet JA, Radegran G, and Roach RC. Hypoxia and the cardiovascular response to dynamic knee-extensor exercise. Am J Physiol Heart Circ Physiol 272: H2655H2663, 1997.

31. Koskolou MD, Roach RC, Calbet JA, Radegran G, and Saltin B. Cardiovascular responses to dynamic exercise with acute anemia in humans. Am J Physiol Heart Circ Physiol 273: H1787-H1793, 1997.

32. Magnusson G, Kaijser L, Sylven C, Karlberg KE, Isberg B, and Saltin B. Peak skeletal muscle perfusion is maintained in patients with chronic heart failure when only a small muscle mass is exercised. Cardiovasc Res 33: 297-306, 1997.

33. Nielsen HB, Bredmose PP, Stromstad M, Volianitis S, Quistorff B, and Secher NH. Bicarbonate attenuates arterial desaturation during maximal exercise in humans. $J$ Appl Physiol 93: 724-731, 2002.

34. Paterson DJ. Potassium and breathing in exercise. Sports Med 23: 149-163, 1997. 
35. Pawelczyk JA, Hanel B, Pawelczyk RA, Warberg J, and Secher NH. Leg vasoconstriction during dynamic exercise with reduced cardiac output. J Appl Physiol 73: 1838-1846, 1992.

36. Piiper J and Scheid P. Model for capillary-alveolar equilibration with special reference to $\mathrm{O}_{2}$ uptake in hypoxia. Respir Physiol 46: 193-208, 1981.

37. Reeves JT, Groves BM, Sutton JR, Wagner PD, Cymerman A, Malconian MK, Rock PB, Young PM, and Houston CS. Operation Everest II: preservation of cardiac function at extreme altitude. J Appl Physiol 63: 531-539, 1987.

38. Reis DJ, Golanov EV, Ruggiero DA, and Sun MK. Sympatho-excitatory neurons of the rostral ventrolateral medulla are oxygen sensors and essential elements in the tonic and reflex control of the systemic and cerebral circulations. J Hypertens Suppl 12: S159-S180, 1994.

39. Roach RC, Koskolou MD, Calbet JA, and Saltin B. Arterial $\mathrm{O}_{2}$ content and tension in regulation of cardiac output and leg blood flow during exercise in humans. Am J Physiol Heart Circ Physiol 276: H438-H445, 1999.

40. Ross CA, Ruggiero DA, Park DH, Joh TH, Sved AF, Fernandez-Pardal J, Saavedra JM, and Reis DJ. Tonic vasomotor control by the rostral ventrolateral medulla: effect of electrical or chemical stimulation of the area containing $\mathrm{C} 1$ adrenaline neurons on arterial pressure, heart rate, and plasma catecholamines and vasopressin. J Neurosci 4: 474494, 1984

41. Rowell LB, Saltin B, Kiens B, and Christensen NJ. Is peak quadriceps blood flow in humans even higher during exercise with hypoxemia? Am J Physiol Heart Circ Physiol 251: H1038$\mathrm{H} 1044,1986$.
42. Sheriff DD and Van Bibber R. Flow-generating capability of the isolated skeletal muscle pump. Am J Physiol Heart Circ Physiol 274: H1502-H1508, 1998.

43. Siggaard-Andersen O. The Acid-Base Status of Blood. Copenhagen, Denmark: Munksgaard, 1974.

44. Stenberg J, Ekblom B, and Messin R. Hemodynamic response to work at simulated altitude, 4,000 m. J Appl Physiol 21: 1589-1594, 1966.

45. Sun MK and Reis DJ. Central neural mechanisms mediating excitation of sympathetic neurons by hypoxia. Prog Neurobiol 44: 197-219, 1994.

46. Torre-Bueno JR, Wagner PD, Saltzman HA, Gale GE, and Moon RE. Diffusion limitation in normal humans during exercise at sea level and simulated altitude. J Appl Physiol 58: 989-995, 1985.

47. Wagner PD, Schaffartzik W, Prediletto R, and Knight DR. Relationship among cardiac output, shunt, and inspired $\mathrm{O}_{2}$ concentration. J Appl Physiol 71: 2191-2197, 1991.

48. Wagner PD, Sutton JR, Reeves JT, Cymerman A, Groves BM, and Malconian MK. Operation Everest II: pulmonary gas exchange during a simulated ascent of Mt. Everest. $J$ Appl Physiol 63: 2348-2359, 1987.

49. Woodson RD, Wills RE, and Lenfant C. Effect of acute and established anemia on $\mathrm{O}_{2}$ transport at rest, submaximal and maximal work. J Appl Physiol 44: 36-43, 1978.

50. Zanzinger J, Czachurski J, and Seller H. Nitric oxide in the ventrolateral medulla regulates sympathetic responses to systemic hypoxia in pigs. Am J Physiol Regul Integr Comp Physiol 275: R33-R39, 1998

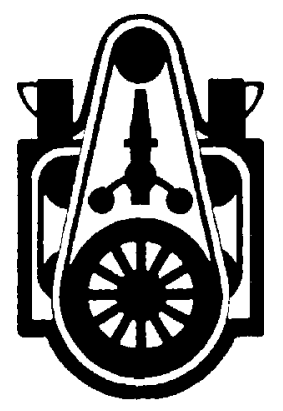

